\title{
The frequency of SLCOIBI*5 polymorphism genotypes among Russian and Sakha (Yakutia) patients with hypercholesterolemia
}

This article was published in the following Dove Press journal:

Pharmacogenomics and Personalized Medicine

25 May 2016

Number of times this article has been viewed

\author{
Dmitrij Alekseevitch \\ Sychev' \\ Grigorij Nikolaevich Shuev ${ }^{2}$ \\ Jana Valer'evna \\ Chertovskih $^{3}$ \\ Nadezhda Romanovna \\ Maksimova $^{3}$ \\ Andrej Vladimirovich \\ Grachev' \\ Ol'ga Aleksandrovna \\ Syrkova ${ }^{2}$ \\ 'Department of Internal Medicine \\ and Clinical Pharmacology, Russian \\ Medical Academy of Postgraduate \\ Education, Moscow, ${ }^{2}$ Faculty of \\ Postgraduate Education, Far Eastern \\ State Medical University, Khabarovsk, \\ ${ }^{3}$ Genetic Laboratory, Ammosov \\ North-Eastern Federal University, \\ Yakutsk, Russian Federation
}

Introduction: Statins are the most commonly prescribed medicines for treatment of hypercholesterolemia. At the same time, up to $25 \%$ of patients cannot tolerate or have to discontinue the statin therapy due to statin-induced myopathy. In a majority of cases, statin-induced myopathy is attributed to $S L C O 1 B 1$ gene polymorphism. The strongest association between statin-induced myopathy and $S L C O 1 B 1$ gene polymorphism was described for simvastatin. Our research was focused on the frequency of $S L C O 1 B 1 * 5$ genetic variant in the Russian population and in the native population of Sakha (Yakutia).

Materials and methods: A total of 1,071 hyperlipidemic Russian and 76 hyperlipidemic Sakha (Yakutian) patients were included in the study. Genotypes of SLCO1B1*5 (c.521T>C, rs4149056) were determined with polymerase chain reaction amplification. The results of our study were compared with data about hyperlipidemic patients in available publications. Results: In the Russian population $665(62 \%)$ patients had $T T$ genotype of SLCO1B1*5, $346(32 \%)$ patients had $T C$ genotype, and in 60 patients (6\%) CC variant was found (HardyWeinberg's chi-square test was $3.1 P=0.21)$. In comparison with Brazil, France, the People's Republic of China, Japan, and the native population of Sakha (Yakutia), $C$-allele, which causes an increased risk of statin-induced myopathy, was found significantly more often in the Russian population. In the native population of Sakha (Yakutia) SLCO1B1 polymorphism was $T T-62$ (82\%), TC- 11 (14\%), CC-3 (4\%) (Hardy-Weinberg's chi-square test was $5.13 P=0.077)$. In comparison with data from Brazil, France, the People's Republic of China, and Japan, $C$-allele frequency in the Sakha (Yakutian) population was not significantly different.

Conclusion: Thus, we have studied the incidence of pathologic SLCO1B1 c.521C-allele in Russian and Sakha hyperlipidemic patients. The presence of SLCO1B1 C-allele in patients with hyperlipidemia forces us to be more careful in hypolipidemic drug prescription, especially statins, according to a higher risk of statin-induced myopathy development. The fact that SLCO1B1 $C$-allele is rarer among Sakha patients, could be interesting from the point of studying adverse drug effects frequency and statins' effectiveness.

Keywords: Russian, Sakha (Yakutia), pharmacogenetics, SLCO1B1, statins, myopathy

\section{Introduction}

Statins are the most prescribed class of hypolipidemic drugs, which have shown high effectiveness for more than 20 years by reducing the risk of myocardial infarction, stroke, and other cardiovascular events. ${ }^{1}$ According to these circumstances, the safeness of statins usage is an important point of scientific research. The frequency of adverse drug effects, particularly statin-induced myopathy, reaches 5\%-10\% per year. ${ }^{2}$ Statininduced myopathy can manifest as myositis and elevated creatine phosphokinase (CPK)
Correspondence: Grigorij Nikolaevich Shuev

Apt. I. bld. 5, ul. Lesnaya, Nekrasovka, Sakhalin Region 694468, Russian Federation

Email shuevgrigorii@gmail.com
Pharmacogenomics and Personalized Medicine 2016:9 59-63

(c) (1) (5) 2016 Sychev et al. This work is published and licensed by Dove Medical Press Limited. The full terms of this license are available at https://www.dovepress.com/terms.

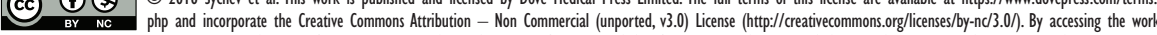
you hereby accept the Terms. Non-commercial uses of the work are permitted without any further permission from Dove Medical Press Limited, provided the work is properly attributed. For permission for commercial use of this work, please see paragraphs 4.2 and 5 of our Terms (https://www.dovepress.com/terms.php). 
level with possible development of dangerous complications like rhabdomyolysis, but the most common form is myalgia without CPK-elevation. ${ }^{3}$ At the present time, the development of statin-induced adverse reactions is usually connected with the action of hepatic organic anion-transporting polypeptide, determined by SLCO1B1. The review of the University of Washington, Seattle, showed that among genetic factors, statininduced myopathy appears to be most strongly associated with variants of $S L C O 1 B 1 .{ }^{4}$ It is known that the carriage of at least one $C$-allele in $S L C O 1 B 1 * 5$ (T521C) is associated with an increased risk of myopathy during treatment with statins. ${ }^{5,6}$ The research of high statin doses in combination with simvastatin revealed a significant increase of the risk of myopathy in $521 C$ carriers. This risk was particularly high in $C C$ genotype carriers, reaching $60 \%{ }^{7}$ Some authors mention the development of statin-induced side effects with other medications, such as atorvastatin in doses $20 \mathrm{mg}$ and higher. ${ }^{8}$ According to possible ethnic differences in genotype abundance, the study of $S L C O 1 B 1$ variants frequency in different ethnic groups of Russian patients with hyperlipidemia is very important for genetic-caused adverse drug reactions forecasting.

\section{Materials and methods}

We used the data of pharmacogenetic tests, conducted in SM Clinic, Moscow, Russia. The first group included 1,071 ethnic Russians (448 men [42\%] and 623 women [58\%]), aged $57 \pm 11$, with IIa and IIb hyperlipidemia types. ${ }^{9}$ All patients were treated with statins. The second group consisted of 76 ethnic Sakha statin-users, including 39 men (51\%) and 37 women (49\%). All of them underwent pharmacogenetic tests in the center of personalized medicine in Republic hospital №3, Yakutsk, Russian Federation. The ethnicity was distinguished by patient's and his/her parent's selfidentification. All patients were genotyped for the allelic variant of $S L C O 1 B 1 * 5$ (c.521T>C, rs4149056). Isolated DNA was extracted from blood leukocytes, using kits of Research and Production Association Lytech (Moscow, Russian Federation). Genotyping was performed by means of real-time polymerase chain reaction equipment of the same manufacturer. The prevalence of allelic variants of the $S L C O 1 B 1^{*} 5$ (c.521C>C, rs4149056) was compared with several similar works of other authors, conducted during last 10 years. We used the data of full-text articles, which were found using PubMed search filters in MEDLINE. We have analysed articles on SLCO1B1 polymorphisms in hyperlipidemic patients. Statistical data was processed, using the chi-square value test for Hardy-Weinberg proportions with the INSTAT program.

\section{Results}

Among 1,071 patients genotyped for $S L C O 1 B 1 * 5$ allelic variant, 665 (62\%) had TT-variant, $346(32 \%)$ had $T C$-variant, and $60(6 \%)$ had CC. $521 T$-allele occurrence was 0.78 and incidence of $521 C$ allele was 0.22 . Genotype frequencies did not deviate significantly from Hardy-Weinberg equilibrium (chisquare $=3.1 ; P=0.21$ ). During genotyping of the second group, it was distinguished that $62(82 \%)$ patients have $T T$-allele, $11(14 \%)$ patients have $T C$-allele, and $3(4 \%)$ patients $C C$ allele. The frequency of $521 T$-allele was 0.89 and $521 C$-allele frequency was 0.11 . The statistically important deviations of genotype distribution from Hardy-Weinberg equilibrium were not observed $\left(\mathrm{X}^{2}=5.13 ; P=0.077\right)$. Genotype $T T$ was regarded as low myopathy risk, $T C$ genotype as moderate risk, and $C C$ as high risk. ${ }^{10}$ During comparison of $T$ - and $C$-allele abundance in research groups, it was distinguished that $C$-allele is significantly more frequent in Russian population (0.22 vs 0.11 ). We have found seven research articles that fitted our design. There was one article written by Brazilian researchers, four articles written in the People's Republic of China, and one paper each from research conducted in France and Japan. ${ }^{11-17}$ We compared $S L C O 1 B 1 * 5$ polymorphism incidence in the Russian population with data of seven other research groups ${ }^{11-17}$ and found that $C$-allele is more frequent in Russian population. Though, there was no significant difference between frequencies of $S L C O 1 B 1 * 5$ polymorphisms in the first group and Japanese data. There were no significant differences in $S L C O 1 B 1 C$-allele abundance after comparison of the second group (Sakha patients) in our research and the data of Japanese, French, Brazilian, and Chinese studies. ${ }^{11-17}$ The results of $S L C O 1 B 1 * 5$ polymorphisms comparison are presented in Table 1 . The study has been approved by the Russian Medical Academy of Postgraduate Education (record no.17). Written consent was obtained from all study participants.

\section{Discussion}

The results of genotyping in the Russian population $(n=1,071$; genotype $T T$ in $62 \%$, genotype $T C$ in $32 \%$, and $C C$ genotype in $6 \%$ of participants, [occurence, $T$-allele $0.78, C$-allele $0.22])$ demonstrate the high $C$-allele incidence of $S L C O 1 B$, which determine a higher risk of statin-induced myopathy. It was revealed that $S L C O 1 B 1 C$-allele is more common in the Russian population, than in Chinese and Brazilian ones. That matches to data about different frequency of this allele according to geographic latitude. It is known that incidence of $c 521 T>C$ varies in individuals of different ethnicities. Moreover, the c.521C incidence decreases from Europe $(14 \%-23 \%)$ to Africa and Asia $(<10 \%) .{ }^{18}$ The 


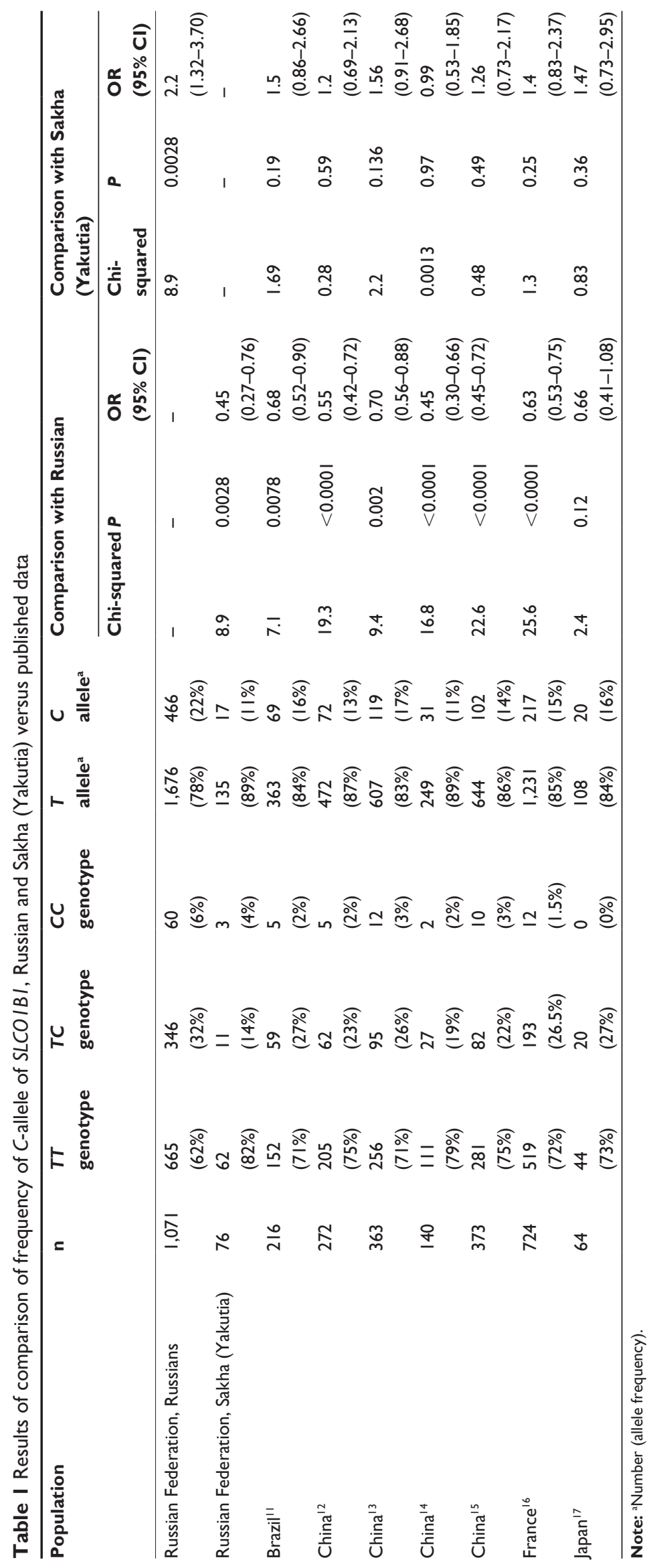


absence of differences in $C$-allele occurrence in Russian and Japanese populations could be caused by a small number of participants in the Japanese study $(n=64)$. It seems that the prevalence of $C$-allele in the Russian population is equal to or higher than that found in the European population. That was confirmed by comparison with the French research. However, the revealed differences could be connected with polyethnicity of participants in this study. After collation of Sakha and Russian populations, statistically significant differences in $C$-allele abundance were found with higher incidence of this allele among Russians. No statistically significant differences were seen in $C$-allele appearance in the Sakha population and populations in Chinese, Brazilian, Japanese, and French studies. The absence of frequency differences of c521C-allele between Sakha patients and ethnic groups in Chinese, Japanese, and Brazilian studies, probably, could be described by the common origin of these populations. ${ }^{19,20}$ The lack of differences between Sakha and French populations is probably connected with ethnic heterogeneity of groups in the French study or with inadequate sample size. In spite of known ethnic differences in $c 521 T$ - and $C$-allele distribution with prevalence of $T$-allele, $C$-allele is responsible for statin-induced myopathy, which can reduce a patient's compliance with possible discontinuation of therapy. ${ }^{2}$ In this view, the experience of personalized statin usage, based on $S L C O 1 B 1 * 5(c .521 T>C, r s 4149056)$ pharmacogenetic tests, is important. In 2011 (updated in 2013) the US Food and Drug Administration has added the warning about the danger of simvastatin admission in $80 \mathrm{mg}$ daily dose as a start therapy. ${ }^{21}$ In 2014, the clinical pharmacogenetics implementation consortium (CPIC) has updated the guideline for SLCO1B1 and simvastatin-induced myopathy. In the new guideline, it has highlighted the correlation between $C$-allele of $S L C O 1 B 1 * 5$ (c.521T>C, rs4149056), especially in homozygotes, and appearance of statin-induced myopathy is the most prominent for simvastatin, but is not so important for other statins. Authors offer to personalize the statin therapy in case of $S L C O 1 B 1 * 5(c .521 T>C, r s 4149056) C$-allele detection by administration of simvastatin $20 \mathrm{mg}$ daily; if the effect of such treatment is insufficient or there are some adverse effects, it is necessary to change the statin. In addition, it can be possible to combine statins with drugs, which interrupt in the gastrointestinal absorption of cholesterol, for example, ezetemib or fibrates. ${ }^{22}$ Such approach to the personalization of statin usage, according to SLCO1B1 pharmacogenetic test, is an object of current interest, especially in view of the recent meta-analysis, which included nine studies. Cases of statin-related myopathy were found to be strongly associated with the variant of $C$-allele, especially receiving simvastatin, but not in those receiving atorvastatin. ${ }^{23}$

\section{Conclusion}

Thus, we have studied the incidence of SLCO1B1 c.521Callele, associated with the risk of statin-induced myopathy, in Russian and Sakha hyperlipidemic patients ( $C$-allele frequency 0.22 and 0.11 ). It was shown that abundance of $S L C O 1 B 1 C$-allele is significantly lower among Sakha patients than in Russian patients, and it is similar to the $C$-allele incidence in Japanese, Chinese, Brazilian, and French studies. Opposite, the $C$-allele incidence in Russians is significantly higher, than in available publications, except of Japanese research. The presence of $S L C O 1 B 1 C$-allele in patients with hyperlipidemia forces us to be more careful in hypolipidemic drug prescription, especially statins, according to a higher risk of statin-induced myopathy development. The fact that $S L C O 1 B 1 C$-allele is rarer among Sakha patients could be interesting from the point of studying of adverse drug effects frequency and statins' effectiveness. The evaluation of the role of other genetic factors $(c .388 A>G, c .463 C>A)$ in statins' adverse effects development in these groups of hyperlipidemic patients is an object for further studies.

\section{Disclosure}

The authors report no conflicts of interest in this work.

\section{References}

1. Baigent C, Keech A, Kearney PM, et al; Cholesterol Treatment Trialists' Collaborators. Efficacy and safety of cholesterol-lowering treatment: prospective meta-analysis of data from 90,056 participants in 14 randomised trials of statins. Lancet. 2005;366(9493):1267-1278.

2. Sewright KA, Clarkson PM, Thompson PD. Statin myopathy: incidence, risk factors, and pathophysiology. Curr Atheroscler Rep. 2007;9: 389-396.

3. Bays H. Statin safety: an overview and assessment of the data-2005. Am J Cardiol. 2006;17;97(8A):6C-26C.

4. Canestaro WJ, Austin MA, Thummel KE. Genetic factors affecting statin concentrations and subsequent myopathy: a HuGENet systematic review. Genet Med. 2014;16(11):810-819.

5. Carr DF, O'Meara H, Jorgensen AL, et al. SLCO1B1 Genetic Variant Associated With Statin-Induced Myopathy: A Proof-of-Concept Study Using the Clinical Practice Research Datalink. Clin Pharmacol Ther. 2013;94(6):695-701.

6. Voora D, Shah SH, Spasojevic I, et al. The SLCO1B1*5 genetic variant is associated with statin-induced side effects. $\mathrm{J} \mathrm{Am} \mathrm{Coll} \mathrm{Cardiol.}$ 2009;54(17):1609-1616.

7. Link E, Parish S, Armitage J, et al; SEARCH Collaborative Group. $S L C O 1 B 1$ variants and statin-induced myopathy a genomewide study. The N Engl J Med. 2008;359(8):789-799.

8. de Keyser CE, Peters BJ, Becker ML, et al. The SLCO1B1 c.521T >C polymorphism is associated with dose decrease or switching during statin therapy in the Rotterdam Study. Pharmacogenet Genomics. 2014;24(1):43-51.

9. Fredrickson DS, Lees RS. A system for phenotyping hyperlipoproteinemia. Circulation. 1965;31:321-327. 
10. Wilke RA, Ramsey LB, Johnson SG, et al; Clinical Pharmacogenomics Implementation Consortium (CPIC). The clinical pharmacogenomics implementation consortium: CPIC guideline for $S L C O 1 B 1$ and simvastatin-induced myopathy. Clin Pharmacol Ther. 2012;92(1): 112-117.

11. Sortica VA, Fiegenbaum M, Lima LO, et al. SLCO1B1 gene variability influences lipid-lowering efficacy on simvastatin therapy in Southern Brazilians. Clin Chem Lab Med. 2012;50(3):441-448.

12. Lee HK, Hu M, Lui SSh, Ho CS, Wong CK, Tomlinson B. Effects of polymorphisms in $A B C G 2, S L C O 1 B 1, S L C 10 A 1$ and $C Y P 2 C 9 / 19$ on plasma concentrations of rosuvastatin and lipid response in Chinese patients. Pharmacogenomics. 2013;14(11):1283-1294.

13. Fu Q, Li YP, Gao Y, et al. Lack of association between SLCO1B1 polymorphism and the lipid-lowering effects of atorvastatin and simvastatin in Chinese individuals. Eur J Clin Pharmacol. 2013;69(6):1269-1274

14. Yang GP, Yuan H, Tang B, et al. Lack of effect of genetic polymorphisms of $S L C O 1 B 1$ on the lipid-lowering response to pitavastatin in Chinese patients. Acta Pharmacol Sin. 2010;31(3):382-386.

15. Hu M, Tomlinson B. Effects of statin treatments and polymorphisms in UGT1A1 and SLCO1B1 on serum bilirubin levels in Chinese patients with hypercholesterolaemia. Atherosclerosis. 2012;223(2):427-432.

16. Couvert P, Giral P, Dejager S, et al. Association between a frequent allele of the gene encoding OATP1B1 and enhanced LDL-lowering response to fluvastatin therapy. Pharmacogenomics. 2008;9(9):1217-1227.
17. Tachibana-Iimori R, Tabara Y, Kusuhara H, et al. Effect of genetic polymorphism of OATP-C $(S L C O 1 B 1)$ on lipid-lowering response to HMG-CoA reductase inhibitors. Drug Metab Pharmacokinet. 2004;19(5):375-380.

18. Pasanen MK, Neuvonen PJ, Niemi M. Global analysis of genetic variation in SLCO1B1. Pharmacogenomics. 2008;9(1):19-33.

19. Fedorova SA, Reidla M, Metspalu E, et al. Autosomal and uniparental portraits of the native populations of Sakha (Yakutia): implications for the peopling of Northeast Eurasia. BMC Evol Biol. 2013;13:127.

20. Matsumoto H. Characteristics of Mongoloid and neighboring populations based on the genetic markers of human immunoglobulins. Hum Genet. 1988;80(3):207-218.

21. FDA: Limit Use of $80 \mathrm{mg}$ Simvastatin 1. FDA Consumer Health Information. U.S. Food and Drug Administration June 2011. Available from: http://www.fda.gov/downloads/forconsumers/consumerupdates/ ucm257911.pdf. Accessed June 8, 2011.

22. Ramsey LB, Johnson SG, Caudle KE, et al. The clinical pharmacogenetics implementation consortium guideline for $S L C O 1 B 1$ and simvastatin-induced myopathy: 2014 update. Clin Pharmacol Ther. 2014;96(4):423-428.

23. Hou Q, Li S, Li L, Li Y, Sun X, Tian H. Association between SLCO1B1 gene $T 521 C$ polymorphism and statin-related myopathy risk: a metaanalysis of case-control studies. Medicine (Baltimore). 2015;94(37): e1268
Pharmacogenomics and Personalized Medicine

\section{Publish your work in this journal}

Pharmacogenomics and Personalized Medicine is an international, peerreviewed, open access journal characterizing the influence of genotype on pharmacology leading to the development of personalized treatment programs and individualized drug selection for improved safety, efficacy and sustainability. This journal is indexed on the American Chemical

\section{Dovepress}

Society's Chemical Abstracts Service (CAS). The manuscript management system is completely online and includes a very quick and fair peer-review system, which is all easy to use. Visit http://www.dovepress. $\mathrm{com} /$ testimonials.php to read real quotes from published authors. 